Licença CC BY Artigo distribuído sob os termos Creative Commons, permite uso e distribuição irrestrita em qualquer meio desde que o autor credite a fonte original.

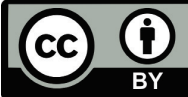

\section{TURISMO E BENS PATRIMONIAIS: A DINÂMICA DA CULTURA CAIÇARA NA ILHA DO MEL - PARANÁ}

\author{
TOURISM AND HERITAGE GOODS: THE DYNAMICS OF CAIÇARA \\ CULTURE IN ILHA DO MEL - PARANÁ
}

TURISMO Y BIENES PATRIMONIALES: LA DINÁMICA DE LA CULTURA CAIÇARA EN ILHA DO MEL - PARANÁ

\author{
PATRÍCIA DENKEWICZ1 \\ BRUNA MORANTE LACERDA MARTINS ${ }^{2}$ \\ CARLOS ALBERTO MARÇAL GONZAGA ${ }^{3}$ \\ EDUARDO HARDER ${ }^{4}$
}

'UNIVERSIDADE ESTADUAL DO PARANÁ, CAMPO MOURÃO, PARANÁ, BRASIL UNIVERSIDADE FEDERAL DO RIO GRANDE, SANTA VITÓRIA DO PALMAR, RIO GRANDE DO SUL, BRASIL

3UNIVERSIDADE ESTADUAL DO CENTRO-OESTE, IRATI, PARANÁ, BRASIL ${ }^{4}$ UNIVERSIDADE FEDERAL DO PARANÁ, MATINHOS, PARANÁ, BRASIL

DATA DE SUBMISSÃO: 09/11/2020 - DATA DE ACEITE: 28/06/2021

RESUMO: O Turismo é uma atividade que promove o deslocamento das pessoas, as quais buscam conhecer novos lugares e obter novas experiências, uma busca pelo prazer. Dessa forma, podese afirmar que a atividade turística é um fator de desenvolvimento das comunidades locais, sendo contribuinte ao desenvolvimento local, o qual pode ser compreendido como a busca pela qualidade de vida de determinada comunidade, tendo os indivíduos que a compõem uma efetiva participação em todo o processo. Como objeto de estudo, abordou-se a llha do Mel, importante atrativo turístico do estado do Paraná, onde localizam-se duas Unidades de Conservação, as quais possuem diretrizes administrativas restritivas para manter a preservação ambiental concomitante às interações culturais promovidas pelo turismo. Dessa forma, o objetivo desta pesquisa centrou-se em analisar a relação entre o turismo e as dinâmicas culturais da comunidade nativa da llha do Mel - PR. A metodologia empregada foi de abordagem qualitativa, cujos instrumentos de pesquisa foram entrevistas individuais e coletivas, observação participante e pesquisa documental. Concluiu-se que o turismo está relacionado às dinâmicas culturais por meio das trocas culturais.

Patrícia: Professora Colaborada, Universidade Estadual do Paraná, Campo Mourão, Paraná, Brasil. Doutora em Meio Ambiente, Universidade Federal do Paraná, Curitiba, Paraná, Brasil. E-mail: patriciadenkwicz@gmail. com. Orcid: https://orcid.org/0000-0002-5045-3222 .

Bruna: Professora Adjunta, Universidade Federal do Rio Grande, Santa Vitória do Palmar, Rio Grande do Sul, Brasil. Doutora em Geografia, Universidade Estadual de Maringá, Maringá, Paraná, Brasil. E-mail: brunamorante@furg.br. Orcid: https://orcid.org/0000-0002-8490-2241 .

Carlos: Professor Associado, Universidade Estadual do Centro-Oeste, Irati, Paraná, Brasil. Doutor em Engenharia Florestal, Universidade Federal do Paraná, Curitiba, Paraná, Brasil. E-mail: gonzaga@unicentro.br. Orcid: https://orcid.org/0000-0001-8446-6112 .

Eduardo: Professor, Universidade Federal do Paraná, Matinhos, Paraná, Brasil. Doutor em Direito, Universidade Federal do Paraná, Curitiba, Paraná, Brasil. E-mail: eduardoharder@gmail.com. Orcid: https://orcid. org/0000-0002-2062-7017 
PALAVRAS-CHAVE: turismo; patrimônio cultural; cultura caiçara; llha do Mel.

ABSTRACT: Tourism is an activity that promotes the displacement of people, who seek to visit new places and obtain new experiences, a search for pleasure. Thus, it can be said that tourist activity is a factor in the development of local communities, contributing to local development, which can be understood as the search for the quality of life of a given community, with the individuals who compose it an effective participation in the entire process. As an object of study, llha do Mel was approached, an important tourist attraction in the state of Paraná, where two Conservation Units are located, which have restrictive administrative guidelines to maintain environmental preservation concomitant with cultural interactions promoted by tourism. Thus, the objective of this research was to analyze the relationship between tourism and the cultural dynamics of the native community of llha do Mel - PR. The methodology used was a qualitative approach, whose research instruments were individual and collective interviews, participant observation and documentary research. It was concluded that tourism is related to cultural dynamics through cultural exchanges.

KEY-WORDS: tourism; cultural heritage; caiçara culture; llha do Mel.

RESUMEN: El turismo es una actividad que promueve el desplazamiento de personas, que buscan descubrir nuevos lugares y obtener nuevas experiencias, una búsqueda del placer. Así, se puede decir que la actividad turística es un factor en el desarrollo de las comunidades locales, contribuyendo al desarrollo local, que puede entenderse como la búsqueda de la calidad de vida en una comunidad determinada, con los individuos que conforman una participación efectiva en todo el proceso. Como objeto de estudio se abordó llha do Mel, importante atractivo turístico del estado de Paraná, donde se ubican dos Unidades de Conservación, las cuales cuentan con lineamientos administrativos restrictivos para mantener la preservación ambiental concomitante con las interacciones culturales promovidas por el turismo. Así, el objetivo de esta investigación se centró en analizar la relación entre el turismo y la dinámica cultural de la comunidad nativa de llha do Mel - PR. La metodología utilizada fue un enfoque cualitativo, cuyos instrumentos de investigación fueron entrevistas individuales y colectivas, observación participante e investigación documental. Se concluyó que el turismo se relaciona con dinámicas culturales a través de intercambios culturales.

PALABRAS CLAVE: turismo; patrimonio cultural; cultura caiçara; llha do Mel.

\section{INTRODUÇÃO}

O turismo é uma prática mundial que envolve diversas interpretações e motivações, o que o caracteriza como um "fenômeno complexo e plural" (Irving, 2015, p. 51). Transita por discussões econômicas, sociais, culturais e ambientais, sendo interpretado ora como "salvador" econômico, ora como "destruidor" de culturas e da natureza preservada. Nesta pesquisa, o turismo é interpretado como uma atividade, primeiramente social, que, além de promover o deslocamento e o consumo da oferta, promove o conhecimento cultural, ambiental e social, possibilita a interculturalidade e a reflexão sobre o mundo em que habitamos (Irving, 2015).

Desde o seu início, o turismo vem crescendo notoriamente e ganhando destaques nas economias mundiais. Nos últimos anos, segundo dados do Ministério do Turismo (2019), a demanda da atividade cresceu cerca de 6\% entre 2017 e 2018 e aumentou sua receita cambial em 8\%, já em 2019, a atividade turística cresceu, em escala mundial, aproximadamente $4 \%$. Entretanto, no Brasil esse crescimento foi mais tímido, representando $1 \%$ na demanda e $2 \%$ 
na receita cambial entre os anos de 2017 e 2018. Essa expansão da atividade representou a chegada de 6,62 milhões de turistas e uma receita cambial de US \$5,92 bilhões (MTur, 2019).

A partir desse crescimento, nas últimas décadas o turismo tem ocupado um papel de destaque nas economias mundiais, sendo considerado uma estratégia econômica, devido ao seu potencial de gerar empregos e de movimentar recursos financeiros. Além disso, o turismo assume, gradualmente, uma importância central nas políticas públicas, já que, por meio dos seus benefícios econômicos, é considerado uma ferramenta auxiliadora na minimização dos problemas sociais contemporâneos, como a pobreza e a desigualdade social, por exemplo (Sancho, 2007).

Entretanto, apesar dos benefícios econômicos sedutores da atividade, há um paradoxo a ser considerado, pois, ainda que o turismo possa representar uma alternativa para a redução das desigualdades sociais e da pobreza, ele também pode ser considerado um gerador de impactos negativos sobre os destinos em que se desenvolve, agravando, por exemplo, o processo de exclusão social e de degradação ambiental e cultural (Sancho, 2007; 2010; Irving, 2015).

No que tange os impactos negativos do turismo sobre a cultura, Banducci e Barreto (2001) destacam que parte das reflexões da antropologia sobre o turismo estão relacionadas à influência que as atividades turísticas exercem sobre a cultura das comunidades receptoras. No entanto, Banducci e Barreto (2001) discutem que existem diversos fatores que também influenciam essa metamorfose cultural, como: a modernização, a mídia, a urbanização, entre outros. Diante disso, os autores sugerem um olhar diferenciado sobre este contexto, o qual se "constitui de negociações simbólicas estabelecidas a partir do contato com o outro" (Banducci \& Barreto, 2001, p. 29). Sendo assim, buscaremos aqui relacionar as reflexões da influência do turismo sobre as culturas locais para os conceitos de interculturalidade e alteridade.

À vista disso, esta pesquisa apresenta como objetivo analisar a relação entre o turismo e as dinâmicas culturais das comunidades nativas da llha do Mel - PR. O local de estudo é um importante atrativo turístico do estado do Paraná, além de ser uma área importante para a conservação da biodiversidade e de ser tombada como Patrimônio Histórico e Artístico do Paraná (IAP, 2012). Com o decorrer do tempo, muitas mudanças ocorreram na llha, desde questões ambientais, culturais e econômicas. Por exemplo, a pesca no passado se constituía na mais importante atividade econômica local, mas foi sendo gradativamente substituída pelo turismo. As áreas destinadas à agricultura de subsistência foram transformadas em áreas de proteção ambiental, circunstâncias que instigam esta pesquisa.

\section{FUNDAMENTAÇÃO TEÓRICA: O TURISMO E OS BENS PATRIMONIAIS - UM CONVITE À INTERCULTURALIDADE}

A cultura é entendida como um movimento dinâmico-conflitivo que apresenta elementos das produções materiais e imateriais da sociedade, congregando a permanência de traços assimétricos e simétricos entre a tradição e o high-tech da modernidade; o local e o transglobal. Este processo dinâmico, chamado por Nestor Canclini (1998) de hibridização, confere a lógica das culturas híbridas, ou seja, o movimento contínuo da interculturalidade. 
Os bens patrimoniais culturais são fontes para compreender os elementos característicos de uma comunidade, neste caso a cultura caiçara. Dessa forma, compreendese o patrimônio como legado cultural formado por bens materiais e imateriais coletivamente significativos e representados como elos das memórias e tradições locais.

Discutem-se as ligações dos bens culturais e o turismo, visando à continuidade histórica do local na presença do global. Sendo assim, o patrimônio cultural está intrínseco no espaço geográfico, pois as paisagens culturais, naturais, os lugares, objetos e saberes remetem à historicidade e às reminiscências (i)materializadas no espaço habitado. Esse entendimento transcende o sentido de oposição entre paisagem natural e a paisagem cultural, pois as suas relações são provenientes das identidades e memórias dos grupos e sujeitos históricos. Devido a isso, os bens patrimoniais e culturais desenvolvem um importante papel para o conhecimento, preservação e ressignificação das categorias geográficas representadas no lugar, tais como paisagem, região e território. Logo, o sentido de pertencimento ao espaço geográfico contribui para reafirmação dos vínculos identitários "[...] recebido do passado, vivenciado no presente e transmitido às gerações futuras" (Pelegrini, 2009, p. 11).

As concepções do termo patrimônio são construídas conforme o contexto em que a sociedade se encontra, de tal modo que se acrescentam inúmeros adjetivos ao vocábulo, tais como ambiental, paisagístico, difíceis, cultural LGBT, hospitalar, industrial, ferroviário, etc. (Carvalho \& Meneguello, 2020). Carvalho e Meneguello (2020) discutem questões de como restaurar, conservar e mantê-lo em segurança, porém o problema mais desafiante na contemporaneidade diz respeito aos usos culturais do patrimônio. Nessa lógica estudam-se alternativas para a gestão do patrimônio cujo objetivo centra-se no desenvolvimento cultural, econômico e social.

De acordo com Barretto (2000) e Ballart Hernández (2008), uma das maneiras de consumir os recursos culturais é por meio do turismo. Assim, trata-se o uso do patrimônio cultural como fomento do turismo, compreendendo a atividade turística como uma prática social de deslocamento que visa ao contato humano e possibilita a troca de experiências entre o turista e a comunidade receptora. No entanto, há uma tensão entre o turismo e os bens culturais, pois, não obstante, "o patrimônio deixa de ser valioso por sua significação na história ou na identidade local e passa a ser valioso porque pode ser "vendido' como atrativo turístico" (Barretto, 2000, p. 32).

Ballart Hernández (2008) adverte que existe um desacordo entre os gestores culturais que defendem a conservação do patrimônio e os que sustentam a preservação e o uso turístico do legado cultural. Os argumentos para limitar o uso dos patrimônios culturais correspondem com a intensidade da deterioração material e a descontextualização histórica e memorial em decorrência da inserção dos bens patrimoniais nos circuitos massivos de comercialização de produtos turísticos.

Carlos (2002, p. 54) expõe que "a produção do espaço turístico descaracteriza o espaço da vida cotidiana, espetaculariza cultura, hábitos e costumes locais [...],". Nessa ótica, o turismo apropria-se dos recursos culturais para o consumo deliberado. Nessa perspectiva, a questão basilar está em como promover o uso do patrimônio cultural pelo turismo, sem tender ao risco da 
mercantilização e simulacros. Para encontrar as respostas para tais preocupações, é importante sinalizar que o patrimônio cultural está disposto em diversificadas formas de materialização, como espaços, objetos, museus, monumentos edificados, assim como, imaterialmente, nas expressões, saberes-fazeres, danças, músicas e outros. E que o incremento desses como bens patrimoniais no mercado turístico deve fomentar a conscientização da comunidade local, no sentido de promover o conhecimento e a proteção desses bens.

Ballart Hernández (2008) afirma que uma das premissas para uma gestão turística do patrimônio cultural é levar em consideração o entrosamento do Estado, do mercado turístico e a comunidade local. Porém, são urgentes políticas públicas integradoras que visem à defesa do meio ambiente, ao patrimônio cultural e ao fomento turístico. Para tanto, os poderes locais das pequenas e médias cidades, de agentes culturais e demais profissionais necessitam superar a ideia de que o turismo se constitui como "indústria sem chaminés", o que, em outras palavras, implica entendê-lo apenas como uma forma de acumulação econômica, cujo resultado é a deterioração dos bens culturais. Assim, o turismo em âmbito local utilizar-se-ia do patrimônio cultural local como atrativo em diversos segmentos (paisagístico, museológico, arqueológico, cinematográfico, gastronômico, religioso etc..), balizado por uma cadeia de ações de pesquisa de inventariação, planejamento participativo e interpretação patrimonial para possibilitar reafirmação de valores da cultura local.

A gestão sustentável do turismo prevê o uso do patrimônio cultural respeitando seus limites. A comunidade local necessita deste encontro com o patrimônio cultural, realizado por meio do turismo para a preservação das memórias e como ferramenta para a interculturalidade. Dessa forma, é preciso ater-se ao fato de que o turismo, pensado como prática social, busca trazer as particularidades dos espaços vividos de cada comunidade e estabelecer parâmetros para o fomento nas dimensões culturais, sociais e econômicas. Por isso, o turismo pode ser praticado como alternativa sustentável para o uso do patrimônio cultural.

\section{RELEMBRANDO A CULTURA CAIÇARA}

O termo caiçara vem do Tupi Guarani caá-içara (Sampaio, 1987), utilizado para denominar as estacas colocadas em torno das tabas ou aldeias e o curral feito de galhos de árvores fincados na água para cercar o peixe.

Segundo a afirmação de Branco e Caseiro (2005), o termo foi designado aos que habitavam as praias, em economia de subsistência baseada na pesca, extração de palmitos e alguns frutos silvestres e em uma pequena agricultura, na qual prevaleciam os roçados de mandioca, milho e arroz. Os ramos, citados na origem etimológica da palavra, eram utilizados na construção das habitações, na preparação das armadilhas para pescar e caçar, e também na proteção do solo cultivado, deixando parte das árvores derrubadas.

De acordo com Adams (2000), são provenientes do resultado da mistura entre portugueses e índios que habitavam o litoral do Paraná, São Paulo e Rio de Janeiro. Geralmente, vivem da pesca artesanal e agricultura de autoconsumo, sendo que praticam a pesca desde sua existência, há cerca de 300 anos, período anterior à criação do barco a motor, que é datado em 1930. De origem japonesa, a pesca realizada por esse povo era e é, em muitos casos, artesanal, pois utiliza um barco sem motor (Branco \& Caseiro, 2005). 
Historicamente, segundo Adams (2000), a formação das comunidades caiçaras só pode ser entendida no contexto da ocupação do litoral brasileiro e dos ciclos econômicos vividos pela região sul/sudeste. O caráter predominantemente agrícola da colonização fez com que as terras férteis, úmidas e quentes das baixadas fossem as mais ocupadas, inclusive graças à facilidade de escoamento dos produtos para o exterior.

Devido a tais ocupações e à banalização preconceituosa sobre esse povo, o caiçara manteve-se isolado na restinga litorânea, onde percebeu-se forçado a estabelecer seu modo de vida de acordo com o ambiente, buscando sua sobrevivência nos traços culturais herdados, assim constituindo uma cultura específica, profundamente adaptada à natureza - ao rio, à serra, ao mar (Branco \& Caseiro, 2005). Sendo assim, sua economia caiçara era caracterizada por uma oposição tanto à economia indígena primitiva, quanto à economia industrial. Seu sistema de produção era organizado para responder, em primeira instância, às necessidades domésticas, mas, ainda assim, o caiçara prescindia de insumos externos, para os quais precisava gerar um excedente: ferramentas, habitação, vestuário, sal, pólvora, entre outros. Além disso, devia oferecer uma contribuição à sociedade nacional sob a forma de impostos (Adams, 2000).

A pesca era uma atividade essencialmente masculina, exceto no caso da pesca da Tainha, que se constituía numa forma de pesca coletiva (arrasto de praia) de grande importância para as comunidades caiçaras. O peixe era um alimento básico, em alguns casos, eram criados galinhas e porcos. No Paraná, a troca entre produtos do mar e da roça era comum (Cunha \& Rougeulle, 1989; Langowiski, s.d.). A função da mulher na sociedade caiçara era a de mãe de família, dona de casa, trabalhadora do lar e da roça. Seu papel era muito importante e essencial para a manutenção do grupo doméstico, sua reprodução, produção e sobrevida. Suas tarefas eram bem definidas: preparo do alimento e criação dos filhos (Cunha \& Rougeulle, 1989; Langowiski, s.d.). Ao marido estavam destinadas as atividades de caça e pesca, derrubada e queimada, construção dos ranchos de moradia, transporte e comercialização dos excedentes agrícolas, condução das canoas e dos trabalhos da roça, plantio e colheita (nestes casos podia ser ajudado pela mulher e filhos) (Marcilio, 1986).

Para as populações caiçaras, as formas de lazer e distração eram as festas, procissões, danças, poucos jogos e os pasquins, espécie de literatura de cordel, a qual relatava a vida nas comunidades (Diegues, 1983 apud Adams, 2000). A dança típica das comunidades caiçaras é o fandango, dança tradicional ibérica, que chegou ao Brasil em meados do século XVIII, dançada pelos colonizadores e seus filhos, o que acabou resultando no "fandango caiçara". A dança acontece sobre o chão de madeira, que corresponde à dança de pares e sapateado, ao som de viola, rabeca, pandeiro e vozes, sendo animada pela aguardente. Atualmente, essa dança encontra-se adormecida, no entanto, alguns grupos de fandango apresentam-se com o intuito de recordar os sons e os passos da cultura tradicional (Branco \& Caseiro, 2005).

Em relação às manifestações religiosas, de acordo com Branco e Caseiro (2005), percebem-se vestígios das tradições portuguesas. O autor Langowiski, (s./d. p. 84) afirma que, normalmente, o caiçara era católico, porém não "[...] no sentido rigoroso do cumprimento das obrigações e preceitos". No entanto, atualmente percebe-se a presença de outras religiões, como por exemplo, o cristianismo evangélico. Já a união dos casais na esfera legal e religiosa, até meados do século XX, não era seguida por toda a comunidade. Sendo a união consensual 
estável a mais praticada. No entanto, em divergência com a forma de uniões entre os casais, a comemoração do casamento era considerada o ápice na vida das caiçaras (Langowiski, s./d.).

A morte era vista como um fenômeno natural e inexorável, sendo o funeral um momento de união e compaixão da comunidade (Marcilio, 1986). E nas relações apresentadas entre vizinhos e parentes, que residem em outras localidades e na ajuda mútua existente na comunidade, revelam-se costumes, que são preservados atualmente, das comunidades europeias, africanas e indígenas, quando estão isolados da sociedade urbana. Nessa perspectiva, salientam-se as relações do caiçara com a vida, pois de acordo com Branco e Caseiro (2005) o povo caiçara é:

[...] simples no viver, direto no sentir e no falar. Entre os mais idosos ainda é forte a característica da "falta de ambição": este desprendimento de riquezas e de bens materiais, esta capacidade de viver bem em condições extremas, o não prever ou se preocupar como amanhã. Não que este povo sofrido tivesse outras oportunidades melhores e as deixasse de lado por puro desprendimento, não. Trata-se sim, de uma arte muito do caiçara, do praiano, de viver bem como tanto que a natureza lhe dá (p. 47).

Ao que diz respeito às habitações caiçaras, apresentavam a mesma estrutura do caipira, sendo com paredes de pau-a-pique, telhado de sapê de duas águas, algumas vezes caiada. O chão era de terra batida e os móveis eram escassos (Carvalho, 1940). Uma grande quantidade de símbolos e figuras dotadas de significados decoravam as habitações (Setti, 1985). Atualmente, algumas coisas mudaram, as paredes e o chão, geralmente, são de madeira e os telhados, em alguns casos, permanecem tradicionais, com sapê de duas águas. Outros passaram a utilizar a telha tradicional. Em relação à educação, segundo os autores Branco e Caseiro (2005), quando se tratava de comunidades caiçaras isoladas, as crianças não frequentavam a escola. A educação, nesses casos, fundamentava-se na vivência da realidade cotidiana, onde se passavam os ensinamentos por meio de histórias, músicas típicas e religiosidade. Os princípios essenciais ensinados eram a coragem, o trabalho, a responsabilidade e a criatividade. Os autores também afirmam que, em muitos casos, as crianças também não possuíam contato com outras crianças e seus brinquedos eram produzidos artesanalmente por elas mesmas, imitando o adulto em seu cotidiano.

Contudo, como já afirmado, a cultura caiçara apresenta algumas alterações provenientes do contato com outras culturas e transformações internas dentro das comunidades. Mourão (1971) considera que, a partir do século XX, no momento chamado de "prosperidade", novas alternativas econômicas foram apresentadas aos caiçaras, resultando no abandono de suas atividades tradicionais e no aumento da população não nativa, a qual era composta por indivíduos oriundos dos centros urbanos. No entanto, em decorrência dessa transformação, nos momentos de estagnação da nova atividade estabelecida, normalmente, a comunidade caiçara retorna a realizar suas atividades tradicionais, resultando em um revezamento em suas atividades econômicas (Mourão, 1971). 


\section{METODOLOGIA}

Para a realização desta pesquisa utilizou-se uma abordagem qualitativa, auxiliada pelos instrumentos de pesquisa participante, pesquisa documental e entrevistas individuais e coletivas, ambas semiestruturadas. Em complemento, foram realizadas observações sobre o cotidiano da comunidade local, seguidas por pesquisas bibliográficas.

O universo de pesquisa constitui-se em 25 entrevistados, cuja identificação no decorrer do texto será realizada por meio de codinomes, por exemplo: Entrevistado 01, Entrevistado 02, Entrevistado 03 e assim sucessivamente. A escolha dos indivíduos ocorreu pelo método bola de neve, o qual é definido como uma amostra não probabilística, que emprega cadeias de referências, isto é, os próprios entrevistados sugerem os possíveis participantes das próximas entrevistas (Vinuto, 2014). Esse método facilitou a identificação e o encontro dos nativos a serem entrevistados, isso devido à indicação dos próprios entrevistados.

As perguntas das entrevistas concentraram-se na identificação das dinâmicas culturais, ou seja, das transformações culturais. Para isso, foram abordados os seguintes pontos: dinâmica das atividades produtivas (turismo, pesca e agricultura), das festividades, da alimentação, das crenças, da religião e das danças típicas.

Em relação à pesquisa documental, esta ocorreu por meio da análise dos documentos produzidos nos espaços de decisão comunitária, ou seja, nas associações. Esses documentos limitaram-se às Atas de reuniões da ANIMPO.

Para analisar os dados, optou-se pela análise qualitativa, a qual pretende compreender o aspecto pluridimensional dos fatos em sua exteriorização natural. Busca-se também absorver os significados distintos de uma experiência vivida (André, 1983). Nessa análise, interliga-se a fala dos sujeitos pesquisados ao contexto em que estão inseridos e delimita-se a abordagem conceitual do pesquisador. A sistematização e interpretação dos resultados é feita por meio dessas interligações entre os discursos dos sujeitos entrevistados e o horizonte teórico do pesquisador (Fernandes, 1991).

\section{LOCAL DE PESQUISA: CARACTERIZAÇÃO DA ILHA DO MEL, LITORAL DO PARANÁ}

A llha do Mel é coberta pela Mata Atlântica, abriga duas Unidades de Conservação - Estação Ecológica e Parque Estadual da llha do Mel - e é considerada Patrimônio Histórico Artístico do Estado do Paraná (IAP, 2004). Pertence ao município de Paranaguá e está inserida no Complexo Estuarino-Lagunar de Iguape - Cananéia - Paranaguá. Compreende uma área de 2.894 hectares, perímetro de $35 \mathrm{~km}$ e está a aproximadamente $2.800 \mathrm{~m}$ de distância do continente (IAP, 2004).

Sua história de ocupação assemelha-se à do litoral paranaense em geral, sendo ocupada inicialmente pelo grupo indígena Guarani, mais especificamente os Mbya (Ladeira, 1990). Posteriormente, chegaram os colonizadores vindos de Portugal para o litoral sul brasileiro em busca de mão-de-obra indígena e riquezas naturais (Maack, 1968, p. 21). Os colonizadores 
portugueses impetraram-se no território indígena a partir da bandeira de Jerônimo Leitão, em 1585 - primeira bandeira encaminhada para as terras do Paraná. Seu objetivo era rechaçar os índios Guaranis e conseguir escravos para trabalhos rurais. Posteriormente, ocorreram várias outras bandeiras, como a de Jorge Correia e Manoel Soero, a de Gabriel de Lara e a do Marquês de Cascais (Figueiredo, 1954). Entretanto, essa ocupação por europeus já acontecia antes da chegada das bandeiras, pois o litoral paranaense já era visitado por grandes navios castelhanos e franceses que buscavam se refrescar. Muitos de seus tripulantes acabavam ficando para conviver com os indígenas (Pelanda, 1999). Atualmente, a população nativa da llha do Mel é formada por caiçaras, que se autodenominam nativos, e por empreendedores turísticos (Gonzaga et al, 2014; Denkewicz, 2016).

A autodenominação de "nativos" pelos caiçaras representa uma autorreferência como descendentes dos antigos habitantes nascidos na llha do Mel. De acordo com Westphal (2014, p. 58), os integrantes das comunidades locais "denominam-se como nativos, desejam ser chamados dessa forma e ao se reconhecerem, legitimam sua identidade e modo de vida tradicional". Portanto, neste trabalho, respeitar-se-á o outro como ele é. Os nascidos na llha do Mel serão chamados de "nativos". Os indivíduos que residem na llha, porém são oriundos de outros lugares, serão denominados como "moradores".

A llha do Mel apresenta-se através de duas características principais, como atrativo turístico e como área de proteção ambiental, ambas vêm historicamente e concomitantemente desenvolvendo-se. O turismo em especial inicia-se, sutilmente, em 1926 com o desenvolvimento dos balneários do litoral paranaense, seguido da construção das primeiras rodovias. Sua intensificação passou a ocorrer na década de 1970, período em que a infraestrutura turística era insuficiente e os moradores locais adaptavam-se para atender à demanda, transformando seus lares em meios de hospedagem (Westphal, 2014).

Nessa época, a llha era administrada pela União Federal, especificamente pela Secretaria de Patrimônios da União (SPU). Ao longo da década de 1970, cinco planos de ordenamento de uso do solo da llha foram apresentados por escritórios de urbanismo sediados em Curitiba: de Rubens Meister, em 1970; de Müller Procopiak, em 1970; da Empresa Paranaense de Turismo (Paranatur), em 1972; de Jaime Lerner, em 1975; e de Ayrton Lolô Cornelsen, em 1980. Todos focaram na exploração econômica do turismo, com visões urbanísticas que "propunham intervenções profundas na llha do Mel" (Harder, 2014, p. 27).

Inicialmente, em 1970, o escritório Müller Procopiak Arquitetos apresentou uma proposta referente à urbanização do local. Na sequência, em 1972, a PARANATUR solicitou ao engenheiro e professor Rubens Meister um Plano Diretor que também visava à urbanização do local. Em 1975, o escritório de Jaime Lerner propôs um projeto semelhante ao de Rubens Meister. No início da década seguinte, em 1980, Rubens Meister apresentou uma atualização de sua proposta (Harder, 2014).

Em 1980, houve também o interesse do engenheiro civil Ayrton Lolô Cornelsen de transformar a llha " [...] em um grande complexo turístico de escala internacional" (Harder, 2014 , p. 27). Esses planos diretores, designados como "planos de aproveitamento turístico", prognosticavam o desenvolvimento do mercado imobiliário e a viabilização do turismo na 
Ilha em moldes de grandes investimentos empresariais (Harder, 2014). Tais planos, de acordo com Harder (2014),

[...] propunham uma radical alteração no modo de vida local, com a construção, por exemplo, de um sistema viário composto por "uma via principal no sentido norte-sul e vias internas às zonas residenciais" (proposta de Jaime Lerner), com previsão de construção de edifícios na orla (Müller Procopiak Arquitetos), ou ainda um zoneamento habitacional com base em classes sociais, no qual os moradores locais seriam alocados em uma zona residencial de classe " $c$ " (Rubens Meister). Previam um acesso marítimo e também aéreo, além da criação de parques com "exibições aquáticas", da "vida primitiva dos nativos", "lojas típicas e restaurantes" e comercialização de souvenirs culturais (Rubens Meister)" (p. 26).

A população local organizou uma manifestação para impedir a execução do projeto de Ayrton Lolô Cornelsen, pressionando socialmente o governo do Estado do Paraná. Em resposta, o governo estadual pleiteou à esfera federal a transferência da gestão da llha do Mel, na forma de aforamento. A iniciativa somou-se "[...] estrategicamente à patrimonialização cultural da ilha, voltada a conter o avanço de uma fronteira econômica ligada ao turismo internacional" (Harder, 2014, p. 29).

Então, foi iniciado o processo de tombamento da llha pelo Departamento do Patrimônio Histórico e Artístico do Paraná (DPHAP), que ocorreu em 16 de maio de 1975. Esse tombamento determinou que toda nova implantação de infraestrutura turística só poderia ser construída depois de aprovada pelo conselho do DPHAP. A finalidade era impedir o desenvolvimento predatório do turismo e conservar os hábitos culturais, bem como a vegetação natural (Denkewicz, 2016).

Nesse sentido, pode-se dizer que as idealizações das UCs foram influenciadas pela mobilização das comunidades locais contra os projetos turísticos. Para conseguir a cessão da gestão da llha junto à Secretaria de Patrimônio da União (SPU), havia uma série de condições a serem seguidas: "[...] preservação do meio ambiente natural e o equilíbrio ecológico, proteção da flora e da fauna e dos bens tombados, reflorestamento, bem assim para execução de plano turístico e de urbanização" (Harder, 2014, p. 20).

Em 1982, o governo estadual obteve o direito de posse da llha. Sendo assim, em 2 de setembro de 1982 iniciou, de fato, o empenho por parte do Estado pela conservação do local (Harder, 2014). Segundo O IAP (2012), o interesse na proteção ambiental transformou a maior parte do território da llha do Mel em áreas protegidas, na forma de Estação Ecológica (ESEC) e Parque Estadual (PE). A criação da ESEC foi firmada por meio do decreto 5.454/1982, o qual afirma que a totalidade dessa área objetiva, em caráter permanente, a preservação da biota, sendo responsabilidade do IAP a administração e a fiscalização desse território (ITCFP, 1986, p. 100). Além do objetivo de preservação, o governo estadual pretendia, com a criação da ESEC, potencializar o impedimento do avanço predatório do turismo que se desenhava na época.

Em relação ao Parque Estadual, sua história iniciou em 1981, quando foi instituído a partir do Relatório 02 do ITCF/CEELIP. Sua viabilização ocorreu por meio do plano de manejo da ESEC da llha do Mel, que anteriormente estabelecia a área como uma Reserva Natural. Entretanto, a denominação Reserva Natural não foi incluída entre as categorias de manejo do Sistema Nacional de Unidades de Conservação (SNUC), instituído pela Lei 9.985/2000. A partir dessa discrepância, surgiu a motivação para a criação do Parque Estadual (Pierre e Kim, 2008). 
Sendo assim, em 2002, foi criado o Parque Estadual da llha do Mel, por meio do Decreto Estadual n 5.506/2002. A área protegida pelo parque é de 337,84 hectares, representando cerca de $12 \%$ da llha. Foi após a criação do Parque que o plano de manejo ganhou uma nova versão, sendo esta apresentada em 2012. Entretanto, os objetivos antigos foram mantidos, apenas uma configuração mais atualizada foi exibida. Em 2009, antes da atualização do plano de manejo, foi criado o plano de uso da llha do Mel por meio da Lei Administrativa 16037/2009. Esse plano de uso é destinado à área de ocupação ao entorno do Parque Estadual e apresenta normativas que regem a administração dessa área pelo IAP (IAP, 2012).

Esses documentos definiram o zoneamento ambiental da llha do Mel e também estabeleceram regulamentações para a vivência na llha. Após o estabelecimento dessas regulamentações, a população local passou a perceber o ônus da conservação, pois algumas atividades cotidianas passaram a ser regulamentadas e limitadas por esses instrumentos. Alguns exemplos incômodos de restrição dizem respeito a construções, reformas, tipos de materiais utilizados nas edificações, áreas de ocupação e festividades, que passaram a depender de autorização prévia do órgão ambiental para se realizarem (Gonzaga et al, 2014; Denkewicz, 2016).

\section{RESULTADOS: A DINÂMICA INTERCULTURAL NA ILHA DO MEL}

A llha do Mel é formada por comunidades caiçaras (Adams, 2000). Inicialmente, percebeu-se que as comunidades da llha são formadas por dois grupos, denominados: nativos, indivíduos que são descendentes dos antigos habitantes, nascidos na llha do Mel; e os moradores, indivíduos originários de outras localidades.

A relação entre tais grupos, em determinados momentos, é conflituosa, pois os moradores entendem os nativos como "povo acomodado, sossegado que possuem pouca pretensão na vida" (Entrevistado 01). Já os nativos afirmam que os moradores demonstram certo preconceito e que opinam em assuntos que deveriam ser tratados essencialmente pelos nativos (Entrevistado 03). No entanto, os nativos reconhecem a importância dos moradores para o desenvolvimento turístico, visto que eles detêm a maior parte da infraestrutura turística.

Outra evidência dessa relação conflituosa foram as propostas, encontradas nas atas de reuniões entre a Associação dos Nativos (ANIMPO) e o conselho gestor, de congelamento dos comércios existentes, em que apenas nativos e moradores efetivos da llha do Mel poderiam oferecer serviços turísticos. A finalidade era limitar as atividades econômicas de moradores temporários, os quais, muitas vezes, não tinham envolvimento com o contexto socioeconômico e cultural da llha do Mel. Além disso, a decisão possibilitou que os nativos se mantivessem com o trabalho turístico e que o avanço da ocupação antrópica fosse dificultado.

No que se refere aos nativos, acredita-se que tal conflito pode ser proveniente do sentimento de pertencimento ao território, o qual está relacionado diretamente à identidade cultural. De acordo com Santos (2003, p. 174), "[...] o território é o chão mais a população, isso é, uma identidade, o fato e o sentimento de pertencer àquilo que nos pertence". Dessa forma, afirma que por meio desse sentimento, em alguns momentos, os moradores podem ser vistos como intrusos que causam determinados problemas. 
Ademais, compreende-se que a atividade turística contribui para a intensificação desse conflito, uma vez que os nativos e os moradores divergem em muitos assuntos relacionados ao desenvolvimento turístico da localidade. A exemplo disso, tem-se o atual contexto da Covid-19, o qual impôs a suspensão das atividades turísticas na llha. Com isso, nativos e moradores passaram a discutir intensamente sobre a possibilidade de retomar a execução das atividades ligadas ao turismo. Enquanto os moradores defendem a reabertura dos equipamentos e serviços turísticos, os nativos lutam pela manutenção das restrições sobre as atividades turísticas, alegando que a llha não possui infraestrutura básica de saúde para atender a um número grande de pessoas e que a movimentação de turistas aumentaria as chances de contaminação. Os nativos acreditam que o cenário ainda não está propício para a retomada das atividades turísticas (Entrevistado 05). Essa divergência em torno do turismo tem acentuado ainda mais a relação conflituosa da população local.

As atividades produtivas, que também podem ser consideradas um elemento do patrimônio cultural, foram impactadas pelas diretrizes ambientais provenientes das UCs. Os impactos causados por tais diretrizes estão diretamente ligados à substituição das atividades econômicas, as quais, inicialmente, eram compostas pela pesca artesanal e pela agricultura de autoconsumo, sendo posteriormente substituídas pelo turismo, atualmente, considerado a principal fonte de renda das comunidades. Segundo a população nativa, essa troca foi facilmente realizada devido à facilidade de trabalhar com o turismo, perante as dificuldades vividas na pesca e na agricultura (Entrevistados $01 ; 02 ; 05 ; 07 ; 10 ; 14 ; 15 ; 17 ; 18 ; 19 ; 21$; 24 e 25). Apesar disso, a pesca ainda ocorre, porém como atividade econômica secundária.

Em relação à agricultura, cultivava-se abacaxi, laranja, banana, milho, mel e mandioca (Entrevistado 11), no entanto, hoje a agricultura não é realizada em nenhuma escala, devido às diretrizes restritivas que os planos de manejo da ESEC e do PE impõem à população local. Tais restrições objetivam a proteção ambiental.

No âmbito da pesca artesanal, esta pode ser interpretada como um elemento cultural que simboliza a herança cultural dos antigos nativos. Atualmente, esta atividade não é tão assídua, uma vez que as comunidades nativas concentram esforços na prática do turismo. Presentemente, somente na comunidade da Ponta Oeste existe a pesca artesanal como fonte de renda primária, em razão do tênue fluxo turístico na comunidade, o qual decorre da falta infraestrutura básica, das diretrizes em prol da proteção ambiental e da distância das demais comunidades. Sob estas circunstâncias, a comunidade da Ponta Oeste não dispõe de infraestrutura turística e básica (água e luz) (Entrevistado 07), contexto que a manteve enraizada nas tradições locais.

Apesar disso, a pesca nas demais comunidades ocorre com maior intensidade entre os meses de maio e julho, período em que se realiza a pesca da Tainha, a qual é praticada em pequena escala e de maneira artesanal. Isso ocorre, de acordo com os pescadores, pois barco não deve possuir motor e nem luz para não espantar o peixe (Entrevistado 03). Desse modo, pode-se afirmar que realizar a pesca de forma artesanal é uma estratégia dos pescadores para obter uma performance mais assertiva na pesca. 
Para a realização da pesca, diversas atividades são realizadas, dentre as quais estão os acampamentos, que são organizados nas praias onde será realizada a pesca. As famílias dos pescadores permanecem acampadas por aproximadamente 45 dias com o propósito de facilitar o desenvolvimento do processo pesqueiro (Entrevistados 03 e 15).

A pesca é considerada símbolo cultural da população da llha do Mel. Além dos elementos culturais da técnica e artefatos, a pesca envolve também o elemento cultural da crença, simbolizado por superstições como: a proibição da presença de mulheres grávidas ou no período menstrual para evitar a evasão dos peixes; mulheres não podem olhar o cardume, pois seu olhar é de cobiça; e não se pode apontar para o cardume ou fazer barulho para não afugentar os peixes (Entrevistado 05).

Após a pescaria, é realizada a Festa da Tainha, que é considerada um patrimônio cultural imaterial, uma vez que, somada aos demais elementos imateriais e materiais, caracteriza a cultura local (UNESCO, 2015). A festa envolve toda população, tendo as tarefas programadas e divididas. É organizada pela Associação dos Nativos da llha do Mel, sendo realizada na terceira semana do mês de julho, com o objetivo de vender o pescado obtido durante os meses anteriores e de intensificar a atividade turística, a qual perde vigor durante o inverno.

A movimentação de turistas aumenta nesse período. Estima-se que cerca de 1500 turistas por dia frequentam o evento (Entrevistado 01). Além da gastronomia e da pesca, a festa apresenta outros elementos culturais, como o forró e as apresentações de fandango (dança típica do litoral do Paraná).

É importante salientar que, por mais que o turismo esteja diretamente vinculado à pesca, a substituição da atividade não ocorreu por ação direta do turismo, uma vez que a proteção ambiental impõe diretrizes que limitam sua prática e, paralelamente, a atividade pesqueira cresceu e embarcações maiores e modernas adentraram o mercado, circunstância que dificultou e restringiu a pesca artesanal nas imediações da llha do Mel.

Acerca da crença como elemento do patrimônio cultural, tem-se a religiosidade dos nativos da llha do Mel. Estes são devotos da Nossa Senhora do Rocio, Santa que, segundo os nativos, ao chegar na llha, em 2003, na Festa de São Pedro, que antecede a Festa da Tainha, trouxe um enorme cardume de Tainhas, cerca de 35 mil peixes, os quais foram pescados 8.134 (Entrevistado 10).

A população, diante de um período ruim na pesca, julgou tal acontecimento como "um milagre", aumentando a devoção pela Santa (Entrevistados 02; 06; 10; 16 e 23). Posteriormente, outras explicações surgiram, como a possibilidade de uma corrente marítima ter direcionado o cardume para a praia. No entanto, a população mantém o acontecimento como um milagre.

Os nativos também são devotos da Nossa Senhora dos Navegantes, para a qual construíram uma igreja na comunidade de Nova Brasília. Além disso, tradicionalmente, realiza-se na primeira semana do mês de fevereiro a Festa de Nossa Senhora dos Navegantes, também em homenagem à Santa. Tal festividade é composta por missas, novenas, procissões marítimas (entre Pontal do Sul e a llha do Mel), churrasco e bingos. Outro Santo recebe a devoção dos nativos 
da llha do Mel: São Pedro. Este é considerado protetor das embarcações e, para homenageálo, realiza-se a Festa de São Pedro, no mês de julho. Cabe ressaltar que outras religiões, além da católica, são praticadas na llha do Mel, entretanto, estas são mais comuns entre os moradores originários de outras localidades.

Além da religião, outro componente do patrimônio cultural são as atividades recreativas. Na llha do $\mathrm{Mel}$, estas estão relacionadas à natureza, como, por exemplo, futebol de campo ou de areia, frescobol, stand up paddle e o surfe, sendo que este se destacou entre os nativos a partir da procura dos turistas pelo esporte. Por conseguinte, atualmente, o surfe é a atividade mais praticada pelos jovens nativos da llha do Mel e sua prática ocorre principalmente na Praia de Fora e na Praia Grande.

Outro elemento do patrimônio cultural é a comida, que antigamente baseava-se na farinha de mandioca, frutas e pescados. E como anteriormente praticava-se o escambo, (sistema de trocas de mercadorias) os moradores, em algumas ocasiões, trocavam peixe por outros alimentos, como por exemplo, o pão.

Relata-se que o Biju, composto pelas sobras da farinha de mandioca, a qual dava origem a uma pasta, posteriormente assada e servida juntamente com café, integrava o cardápio como de um dos principais pratos da época. Banana amassada com farinha de mandioca, siri metido a besta (siri com arroz), Arroz Lambe-Lambe (a base de mariscos), peixe defumado e carne seca também compunham o cardápio. Em geral, o cardápio era constituído por alimentos resistentes à falta de refrigeração, visto que na época não havia eletricidade na llha, circunstância que impedia, por exemplo, o funcionamento de refrigeradores.

Atualmente, as refeições assemelham-se à alimentação das demais localidades litorâneas. Normalmente, a população alimenta-se de feijão, arroz, peixe, frutos do mar, carnes, massas, saladas e frutas. Entretanto, os legumes, as verduras e as frutas são limitadas, devido à limitação de transporte do continente para a llha. À vista disso, costuma-se trazer os mais resistentes como: cenoura, repolho, beterraba, tomate, banana, mamão, melão, etc. O prato típico atual é a tainha assada (Entrevistados 01; 03; 07; 09 e 10).

No que tange às bebidas, a Cataia, também conhecida como Whisky Caiçara, é considerada típica. Essa bebida é produzida a partir da imersão das folhas da Cataia (Pimenta Pseudocaryophyllus Var. Hoehnei) na cachaça. De acordo com Bazzo (2010), inicialmente, no Estado do Paraná, a bebida foi produzida na comunidade de Barra do Ararapira e, com o decorrer do tempo, foi disseminando-se para as demais comunidades do litoral paranaense. Segundo Morgante et al. (2010), a bebida é considerada um produto de grande importância cultural e econômica para as comunidades da região.

Apesar do grande consumo da bebida nos períodos anteriores, hoje, em meio à diversidade de bebidas, e ao fácil acesso a estas, foram inseridas novas bebidas à realidade cotidiana da população nativa, como, por exemplo: cerveja comercial e artesanal, whisky, vodka, caipirinha, vinhos, entre outros.

Outro importante elemento do patrimônio cultural é o fandango, dança típica da região. Antigamente, costumava-se dançar e tocar fandango nas festas realizadas pela 
comunidade. A banda era formada pelos próprios nativos, os quais tocavam sanfona, pandeiro e zabumba (Entrevistados 04; 08; 12). O fandango é conhecido popularmente como forró arrasta pé, devido à forma como se dança. Foi registrado pelo Iphan, em novembro de 2012, como patrimônio imaterial, considerado uma expressão musicalcoreográfica-poética e festiva que ocorre no litoral sul do Estado de São Paulo e no litoral norte do Estado do Paraná (IPHAN, 2012).

Presentemente, o fandango é pouco praticado, sua apresentação foi lentamente substituída por outras formas de danças e estilos de músicas. Assim, novos ritmos foram incorporados à cultura local, como, por exemplo, o reggae, o sertanejo universitário, o funk, o pop rock, o jazz, entre outros. As mudanças ocorridas nos hábitos alimentares foram influenciadas, especialmente, pela instalação da energia elétrica, circunstância que possibilitou a refrigeração dos alimentos e, consequentemente, diversificou a alimentação caiçara. Considera-se que a chegada de novos moradores à llha também influenciou nessa transformação, pois houve a inserção de novos hábitos alimentares, como, por exemplo, a inclusão de novos pratos à cultura local - chimarrão e churrasco.

Pela prática do turismo, novos indivíduos se deslocam para llha, seja para visitar ou fixar residência, causando um encontro cultural, o qual resultou em alterações de ambas as culturas. Especificamente na cultura caiçara, novos costumes foram inseridos, de modo que, em alguns casos, os antigos costumes foram substituídos. Contudo, tal transformação do patrimônio cultural não ocorreu por meio de imposição violenta, como ocorre, por exemplo, no etnocentrismo, mas sim por meio de trocas culturais, as quais ocorreram cotidianamente por via da alteridade e interculturalidade. Esse pensamento justifica-se porque a alteridade, segundo Fleuri (2003, p. 497), "trata-se do desafio de se respeitar as diferenças e de integrá-las em uma unidade que não as anule, mas que ative o potencial criativo e vital da conexão entre diferentes agentes e entre seus respectivos contextos", conjuntura identificada na llha do Mel durante o período pesquisado.

Ao mesmo passo está a interculturalidade, que, de acordo com Freitas (2012, p. 83), é a tentativa de "equacionar e decifrar a difícil gramática da convivência entre os diferentes, respeitando as particularidades sem perder a perspectiva da igualdade no sentido da salvaguarda da dignidade humana". Compreende-se que, mesmo que existam exceções, a maior parte dos encontros culturais entre nativos e turistas acontecem de maneira gentil e respeitosa, circunstância que permite a troca cultural sem prejuízo para ambas as partes.

Embora o turismo possibilite a troca cultural, favorecendo posteriormente as alterações dos patrimônios culturais, esta atividade, de acordo com os dados levantados, não foi o principal fator na viabilização dessa alteração, foi a energia elétrica. O desenvolvimento das atividades turísticas pode ter acelerado a instalação da energia elétrica na llha, mas já estava em execução um processo de eletrificação do litoral paranaense. Segundo a Companhia Paulista de Força e Luz (CPFL, 2017), o processo de evolução da sociedade possibilitou a criação de diversos instrumentos que facilitaram a realização das atividades humanas cotidianas, proporcionando maior conforto e acelerando o desenvolvimento socioeconômico das sociedades. Dentre esses instrumentos está a energia elétrica, a qual foi gradualmente chegando aos países, cidades e comunidades, independentemente da existência da atividade turística. 
Esse contexto reafirma o argumento de Banducci e Barreto (2001), de que existem diversos fatores que influenciam a metamorfose do patrimônio cultural, como a modernização, a mídia, a urbanização, entre outros. Sendo assim, as alterações culturais ocorridas nas comunidades da llha do Mel são provenientes da própria dinâmica cultural das relações interculturais. O turismo não é o vilão das transformações culturais. Percebeuse que o desenvolvimento da atividade turística na llha do Mel tem proporcionado a troca cultural entre turistas e nativos, a divulgação cultural e o enriquecimento cultural, uma vez que a troca pode resultar na inserção de novos costumes. Isso se caracteriza como um contexto positivo quando baseado nos princípios da alteridade e da interculturalidade.

Apesar disso, não se descarta a necessidade da criação de estratégias que valorizem e protejam a memória cultural das comunidades nativas. No discurso dos nativos entrevistados, é evidente o esquecimento de alguns elementos culturais. Há uma nova geração de habitantes na llha do Mel, confrontando dialeticamente saberes e certezas de seus antepassados, criando novos significados e elaborando uma nova realidade cotidiana. O distanciamento dos jovens das antigas atividades produtivas, pesca e agricultura, assim como a assimilação de uma nova gastronomia e gosto musical, evidenciam as transformações em curso. Nesse distanciamento, especialmente das atividades socioeconômicas, o turismo ganha centralidade. Tal circunstância pode ser positiva, visto que o desenvolvimento do turismo cultural planejado pode viabilizar a valorização cultural local (Denkewicz, 2020). Para uma gestão não disruptiva do patrimônio cultural, Ballart Hernández (2008) recomenda uma governança territorial cooperativa entre o Estado, empresários do turismo e comunidade local.

\section{CONSIDERAÇÕES FINAIS}

A presente pesquisa buscou analisar a relação entre o turismo e as dinâmicas culturais da comunidade nativa da llha do Mel, PR. Nesse sentido, observou-se que o turismo se relaciona à dinâmica cultural por meio do encontro entre turistas, nativos e moradores, em que as trocas culturais são constantes. Essa circunstância, inevitavelmente, intensifica a dinâmica das mudanças culturais em andamento.

Diversos bens culturais imateriais vivenciam essa dinâmica das mudanças culturais, como, por exemplo, as atividades produtivas da pesca e agricultura, que foram substituídas pelo turismo; os alimentos e bebidas, os quais tornaram-se muito semelhantes aos hábitos alimentares dos turistas e moradores; as crenças religiosas, que atualmente abrangem novas religiões; as músicas, danças e as atividades de lazer, as quais também foram alteradas por meio do abandono parcial de tais elementos culturais e pela inclusão de novos ritmos e atividades. No entanto, o turismo não foi o único influenciador dessas mudanças, uma vez que elas estão relacionadas a um conjunto de fatores decorrentes dos contextos socioeconômicos locais e globais. O contexto estudado nos revelou que o encontro cultural promovido pelo turismo na Ilha do Mel estava baseado na alteridade e interculturalidade, apesar do desconhecimento desses processos pelos atores envolvidos. Compreende-se que o turismo está inerentemente relacionado às dinâmicas das trocas culturais, as quais podem contribuir com as mudanças culturais a longo prazo. Contudo, quando esse processo de alterações culturais ocorre por 
meio da alteridade e da interculturalidade, ele passa a compor a própria dinâmica da cultura, a qual está cada vez mais acelerada na sociedade globalizada. Apesar disso, não se pode esquecer que tais relações redefinem as relações de poder e os conflitos potenciais entre os atores sociais envolvidos.

Nesse contexto, o desenvolvimento do turismo poderia ser planejado à luz da sustentabilidade, buscando a proteção e a valorização cultural local. Sob essa perspectiva, o turismo tornar-se-ia uma possibilidade viável para a manutenção cultural, uma vez que possibilitaria o destaque da cultura caiçara como atrativo turístico, um processo capaz de auxiliar na promoção e possível valorização cultural. Os resultados desta pesquisa contribuem para o entendimento dos bens culturais enquanto forma de representação da cultura das populações caiçaras, que resistem às formas de apropriação da cultura de massa e o risco de homogeneização dos elementos que compõem a uma comunidade tradicional, formada pelos nativos e moradores da llha do Mel. Outro contributo desta pesquisa foi que o turismo destaca-se enquanto elemento de promoção dos bens culturais da cultura caiçara, sendo que essa atividade econômica influencia a permanência e a resistência da comunidade local, cujo papel é componente central de fortalecimento de vínculos de pertencimento.

As limitações da pesquisa circunscreveram-se em verificar como os bens culturais da cultura caiçara estão presentes na dinâmica socioeconômica na atualidade da llha do Mel - PR, que é experienciada a partir das relações assimétricas dos nativos, moradores e turistas. O horizonte de investigações sobre este assunto permite desenvolver estudos futuros que acompanhem a dinâmica da cultura caiçara na llha do Mel e que reflitam sobre estratégias capazes de auxiliar na valorização cultural local.

\section{REFERÊNCIAS}

Adams, C. (2000). As populações caiçaras e o mito do bom selvagem: a necessidade de uma nova abordagem interdisciplinar. Revista de Antropologia, 43(1), 145 - 182.

André, M. E. D. A. (1983). Texto, contexto e significado: algumas questões na análise de dados qualitativos. Cadernos de Pesquisa, 45(1), 66-71.

Ballart Hernandez, J. (2008). Usos del patrimônio, acción social y turismo: hacia um necessário consenso. Diálogos, 12(1), 1-20.

Banducci Jr. A; Barretto, M. (Orgs.). (2001). Turismo e Identidade local: uma visão antropológica. Campinas, SP: Papirus.

Barretto, M. (2000) Turismo e legado cultural: as possibilidades do planejamento. Campinas, SP: Papirus.

Bazzo, J. (2010). Mato que vira mar, mar que vira mato: o território em movimento na vila de pescadores da Barra de Ararapira (Illha do Superagui, Guaraqueçaba, Paraná). (Dissertação de mestrado). Universidade Federal do Paraná, Curitiba, PR, Brasil.

Branco, A.; Caseiro, F. (2005). Cultura Caiçara: resgate de um povo. Peruíbe - São Paulo: Ełecê.

Canclini, N. (1998). Culturas híbridas: estratégias para entrar e sair da modernidade. São Paulo: Edusp.

Carlos, A. F. A. (2002). O Turismo e a produção do Espaço. Revista Geografia e Ensino, 8(1), 47-56. 
Carlos, A. F. A. (1982). O turismo e a produção do espaço. Revista Geografia e Ensino, 1, s/p.

Carvalho, M. C. (1940). O pescador no litoral do Estado de São Paulo. Florianópolis, Santa Catarina, Brasil.

Carvalho, A., \& Meneguello, C. (2020). Dicionário temático de patrimônio: debates contemporâneos. Campinas: UNICAMP.

Coriolano, L. N.; Vasconcelos, F. P. (2014). Lazer e turismo: novas centralidades da sociedade contemporânea. Revista Brasileira de Estudos do Lazer, 1 (2), 3-22.

Companhia Paulista de Força e Luz - CPFL. (2017). História da Energia Elétrica. Recuperado de https://www.cpfl.com.br/energias-sustentaveis/eficiencia-energetica/uso-consciente/historia-daenergia/Paginas/default.aspx.

Cunha, L. H., \& Rougeulle, M. D. (1989). Comunidades litorâneas e unidades de proteção ambiental: convivência e conflitos: o caso de Guaraqueçaba, Paraná. São Paulo: USP.

Denkewicz, P. (2016). Cultura e natureza: desenvolvimento comunitário na llha do Mel, Paraná (Dissertação de mestrado). Universidade Estadual do Centro Oeste, Irati, PR, Brasil.

Denkewicz, P. (2020). Turismo, proteção ambiental e inclusão social na llha do Mel, litoral do Paraná. (Tese de doutorado). Universidade Federal do Paraná, Curitiba, PR, Brasil.

Fernandes, M. E. (1991). Memória Camponesa. In: Anais da $21^{a}$ Reunião Anual de Psicologia, SPRP (p. 20). Ribeirão Preto.

Figueiredo. J.C. (1954). Contribuição a Geografia da llha do Mel (litoral do estado do Paraná) (Tese de doutorado). Faculdade de Filosofia da Universidade Federal do Paraná, Curitiba, PR, Brasil.

Fleuri, R. M. (2003). Intercultura e Educação. Revista Brasileira de Educação, 1 (23), 18-35.

Freitas, F. S. (2012). A diversidade cultural como prática na educação. Curitiba: InterSaberes.

Gonzaga, C. A. M., Denkewicz, P., \& Prado, K. C. P. (2014). Unidades de Conservação, ecoturismo e conflitos socioambientais na llha do Mel, PR, Brasil. Revista ADMPG, 7(1), 61-67.

Harder, E. (2014). A constitucionalização dos direitos culturais no brasil e os sentidos de uma perspectiva patrimonial (Tese de doutorado). Universidade Federal do Paraná, Curitiba, PR, Brasil.

Instituto Ambiental do Paraná. (2012). Plano de Manejo do Parque Estadual da llha do Mel [Site]. Recuperado de http://www.iap.pr.gov.br/arquivos/File/Plano_de_Manejo/PE_llha_do_Mel/ anexo_4_03.pdf.

Instituto Ambiental do Paraná. (2004). Plano de controle ambiental e uso do solo da llha do Mel [Site]. Recuperado de https://docs.ufpr.br/ edugeo/Planos_Litoral/PlanoDiretor_llhadoMel/Plano_llha_ Completo.pdf.

Instituto de Terras, Cartografia e Florestas do Paraná - ITCFP. (1986). Coletânea de Legislação e Documentação sobre a llha do Mel. Curitiba: ITCFP.

Instituto do Patrimônio Histórico e Artístico Nacional- IPHAN. (2020). Fandango Caiçara [Site]. Recuperado de http://portal.iphan.gov.br/pagina/detalhes/83.

Instituto do Patrimônio Histórico e Artístico Nacional- IPHAN. (2012). Parecern 17/2012 da Coordenação Geral de Identificação e Registro do Departamento do Patrimônio Imaterial - IPHAN. Acesso em junho de 2021. Disponível em http://portal.iphan.gov.br/uploads/ckfinder/arquivos/Parecer_DPI_ fandango_caicara(1).pdf. 
Irving, M. (2015). Turismo, áreas protegidas e inclusão social: uma triangulação necessária em planejamento, no caso brasileiro. In: M. Irving, C. G. RODRIGUES, A. RABINOVICl, \& H. A. COSTA. Turismo, Áreas Protegidas e Inclusão Social: diálogos entre saberes e fazeres ( $1^{\mathrm{a}} \mathrm{ed}$.). Rio de Janeiro: Letra e Imagem.

Ladeira, M. I. (1990). Os índios Guarani e as Ilhas do Paraná. Brasília: Centro de trabalho indigenista.

Langowiski, V. B. R. (s/d., 77-101). Contribuição para o estudo dos usos e costumes do praieiro do litoral de Paranaguá, Jornal de Paranaguá.

Maack, R. (1968). Geografia física do Estado do Paraná. Curitiba: BRDE/IBPT/UFPR.

Marcilio, M. L. (1986). Caiçara: terra e população. Estudo de demografia histórica e da história social de Ubatuba. São Paulo: Edições Paulinas/CEDHAL.

Ministério do Turismo. (17 de setembro de 2020). Atividade turística cresce 4,4\% em julho. Fonte:MTUR:http:// www.turismo.gov.br/\%C3\%BAltimas-not\%C3\%ADcias/12964-atividade-tur\%C3\%ADstica-cresce-4,4-emjulho,-aponta-ibge.html\#: :text=Os\%20dados\%20da\%20PMS\%20(Pesquisa,mesmo\%20m\%C3\%AAs\%20 do\%20ano\%20passado.\&text=Em\%20julho\%2C\%20esse\%20crescimento\%20(4,mesmo\%.

Morgante, P. G. et al (2010). Cataia: muito consumida, pouco conhecida. Em R. B. SILVA, \& L. C. MING, Polo de Biotecnologia da Mata Atlântica: relatos de pesquisas e outras experiências vividas no Vale do Ribeira (pp. 20-40). Jaboticabal: Maria Lourdes Brandel.

Mourão, F. A. A. (1971). Os pescadores do litoral sul de São Paulo. Um estudo de sociologia diferencial. (Tese de Doutorado). Universidade de São Paulo, São Paulo, SP, Brasil.

Organização das Nações Unidas para Educação, C. E.-U. (2015). Cultura y desarrollo. Acesso em 10 de agosto de 2020, disponível em http://www.unesco.org/.

Pelanda, W. R. (1999). Os processos erosivos na llha do Mel e as suas consequências socioeconômicas (Paranagua-PR). Curitiba: UFPR.

Pelegrini, S. C. (2009). Patrimônio Cultural: consciência e preservação. São Paulo: Ed. Brasiliense.

Pierre, N., \& KIM, M. K. (2008). A sustentabilidade social como condição para a conservação: o caso da llha do Mel - Paraná, Brasil. Brasília. Acesso em 07 de Junho de 2019

Sampaio, T. (1987). O Tupi na geografia nacional. Brasília: Ed. Nacional.

Sancho, A. (2007). Turismo: Alternativa Efetiva de Inclusão Social? Uma reflexão sobre as Políticas Públicas de Turismo no Brasil. (Dissertação de Mestrado). Universidade Federal do Rio de Janeiro, Rio de Janeiro, RJ, Brasil.

Sancho, A. (2010). Interpretando o Plano Nacional de Turismo 2003/2007 sob a ótica da inclusão social. Caderno Virtual de Turismo, 10(3), pp. 103-120.

Santos, M. (2003). Por outra globalização do pensamento único à consciência universal. Rio de Janeiro, RJ, Brasil. Acesso em 15 de setembro de 2020, disponível em http://inseer.ibict.br/ciga/index.php/ ciga/article/viewFile/51/39.

Setti, K. (1985). Ubatuba nos cantos das praias: estudo do caiçara paulista e de sua produção musical. São Paulo: Ática.

Vinuto, J. (2014). A amostragem em bola de neve na pesquisa qualitativa: um debate em aberto. Temáticas, 22 (44), 203-220. 
Westphal, E. (2014). Para além do paraíso: uma reinterpretação sociológica do discurso ambiental sobre as identidades de grupos tradicionais e de suas praxis religiosas populares na llha do Mel. (Tese de Doutorado). Universidade Federal do Paraná, Curitiba, PR, Brasil.

Contribuição de cada autor na construção do artigo

Patrícia Denkewicz: Concepção e elaboração do manuscrito. Análise de dados, participação ativa da discussão dos resultados, revisão e aprovação da versão final do trabalho.

Bruna Morante Lacerda Martins: Elaboração do manuscrito, participação ativa da discussão dos resultados, revisão e aprovação da versão final do trabalho.

Carlos Alberto Marçal Gonzaga: Elaboração do manuscrito, revisão e aprovação da versão final do trabalho.

Eduardo Harder: Elaboração do manuscrito, revisão e aprovação da versão final do trabalho. 